\title{
ADHD: science, stigma and service implications
}

\author{
B. Gavin ${ }^{1,2}$ and F. McNicholas ${ }^{1,2,3, *}$ \\ ${ }^{1}$ School of Medicine, University College Dublin, Dublin, Ireland \\ ${ }^{2}$ Geary Institute, UCD, Belfield, Dublin, Ireland \\ ${ }^{3}$ Lucena Clinic Rathgar, Our Lady's Hospital Crumlin, Dublin, Ireland
}

\begin{abstract}
We are delighted to dedicate an edition of the Irish Journal of Psychological Medicine to the topic of attention-deficit hyperactivity disorder (ADHD). ADHD accounts for the majority of clinical presentations to Child and Adolescent Mental Health Services, both in terms of new assessments and ongoing attendances. Papers presented in this edition reflect on the evolving construct of ADHD, drawing from science, clinical practice and public opinion. Current and evidenced-based assessment and treatment practice guidelines are reviewed. International longitudinal studies allow us to understand the personal and societal cost, which can persist for many years post-diagnosis. Despite continuation to adulthood in many young people, follow on adult services are lacking. It is fitting that submissions, by way of personal reflections and opinion pieces, are also included from adult colleagues as they reflect on their experiences in this area. Given the recent development of a national clinical programme in ADHD in Ireland, coupled with a growing evidence for effective interventions, it is hoped that this special edition will highlight the need for appropriate and accessible ADHD treatments across the lifespan.
\end{abstract}

First published online 24 May 2018

Key words: ADHD, Hyperkinetic disorder, Service Implications.

\section{Construct evolution}

Like many medical and psychiatric illnesses, the concept of attention-deficit hyperactivity disorder (ADHD) has benefited from refinement and revision in response to accumulation of knowledge and scientific enquiry. The concept or condition now termed ADHD in existence since 1987, is not a new phenomenon; the medical literature contains descriptors of ADHD like symptoms since the early 20th century. Indeed Hippocrates, described patients who had 'quickened responses to sensory experiences...because the soul moves on quickly to the next impression'. In 1902 the core symptoms we now recognise as ADHD were called 'Morbid Defect of Moral Control' followed by 'Encephalitic Brain Disorders' in 1922. With the advent of a formal diagnostic classification system for all diseases, Diagnostic and Statistical Manual, or DSM, first edition in 1952 (DSM I (1952), 1st edn), this allowed for careful classification of illness. ADHD like features were included in the second edition (1968) (DSM-II (1968), 2nd edn), under the name of Hyperkinetic Impulse Disorder, and with each subsequent edition refined and renamed to Attention Deficit Disorder (ADD) in 1980 (DSM-III (1980), 3rd edn) and finally ADHD in DSM-III Revised (1987) (DSM-III (1987), 3rd edn, revised) and subsequently retained.

\footnotetext{
* Address for correspondence: F. McNicholas, School of Medicine, University College Dublin, Dublin, Ireland.

(Email: fionamcn2008@gmail.com)
}

\section{Epidemiology}

ADHD represents one of the commonest mental health conditions of childhood. It is the most frequent reason for attendance at Child and Adolescent Mental Health Services (CAMHS) in Ireland (based on CAMHS annual reporting, up to $50 \%$ of children attending CAMHS meet diagnostic criteria) (HSE, 2014); although huge variation in prevalence rates between studies and across countries exist, from lows of $0.5 \%$ to highs of $26 \%$, which reflect methodological issues (Skounti et al. 2007), when robust diagnostic criteria are applied, there is a uniformity of rate set at about $5.6 \%$ worldwide, with consistency in boys outnumbering girls (Biederman et al. 2004; Novik et al. 2006; Willcutt, 2012). In the meta-analysis of these prevalence studies, ADHD prevalence is constant across socio-economic groups and unaffected by factors such as urbanicity. Indeed, epidemiological studies which have examined the prevalence of ADHD across the globe have established that the incidence of core ADHD symptoms is highly consistent despite stark cultural differences (Polanczyk et al. 2007).

\section{Knowledge and attitudes}

Factors such as cultural attitudes (DSM-V, 2013), public awareness and understanding of the condition vary greatly, however, as does the knowledge and acceptance of the validity of the diagnosis among professional groups including clinicians working in mental health services as well as those within the broader health sector 
(Wright et al. 2015). In addition, knowledge is very limited among key professional groups such as teachers and GPs, each of whom could play a key role in facilitating early detection and intervention (Tatlow-Golden et al. 2017). Consequent to these and a myriad of factors in service provision, sadly, in Ireland, as in many other countries, ADHD remains underdiagnosed and undertreated (Hayden et al. 2015; Sayal et al. 2017).

\section{Diagnostic scepticism}

The basis for this lack of acceptance of ADHD as a valid diagnosis relative to other psychiatric diagnoses is undoubtedly complex in origin (Singh, 2008). Nonetheless that such doubt still exists, and at the level it does, is surprising given that the neurobiological framework, validity and inter-rater reliability of diagnostic symptoms and treatment effectiveness are as robust, if not more so, than a range of other psychiatric diagnoses including mood disorders and psychotic disorders (Dickstein et al. 2006; Ellison-Wright et al. 2008; Davenport et al. 2010; Proal et al. 2011; Cortese et al. 2012). Indeed, many scientific articles on ADHD, including some in this special edition, refer to the controversial nature of the diagnosis. That the same is not true of scientific articles on the subject matter of depression, bipolar disorder, psychosis or schizophrenia is worthy of consideration and reflection. Although it is correct to be concerned about over medicalisation of behaviour, and over medication in any age group, the real issue, at least in United Kingdom and Ireland (Timimi \& Taylor, 2004), is one of underdiagnoses and treatment, with ambivalent medical rather than public attitudes contributing to the low referral, diagnosis and treatment rates (Sayal et al. 2002; Sayal et al. 2017). Furthermore, there is little attention to ADHD as a lived experience for the child or consideration of how interactions between individual biology and particular environmental inputs might give shape and meaning to symptomatic behaviours, and to the success of interventions. This is a significant gap in the literature on ADHD especially, given that children carry this diagnosis in the midst of complex and highly contested social and medical territories (Singh, 2011).

\section{Early intervention}

The concept of Early Intervention is broadly accepted in medicine and more latterly in psychiatry particularly in illnesses such as psychosis (McGorry \& Killackey, 2002). By its nature, ADHD is uniquely well suited to this paradigm. ADHD impacts multiple facets of children's lives; school, home, friendships and relationships. Children with ADHD are exposed to higher levels of criticism and hostility in these environments, commonly contributing to lower self-esteem, self-efficacy and self-belief (Caci et al. 2014). Children with ADHD are less likely to experience success in academic, extracurricular and other settings such as sport, which often has a profoundly demotivating impact; children who have never fulfilled their true potential and have rarely experienced success may fail to see the value of persistence, effort and application. Clearly the presence of ADHD shapes life experience which in turn shapes aspects of personality formation. The earlier the child's difficulties are recognised as representing ADHD, the quicker behaviours can be positively reframed and interventions put in place to support the child, parents and school teachers. Parents frequently cite diagnosis as the single most important intervention they obtain in mental health services; the understanding that emanates from early, accurate diagnosis empowers parents to focus on recovery rather than the cycle of guilt and blame that parents and undiagnosed adults with ADHD frequently describe as being a hallmark of their lives with unending criticism the commonest soundtrack.

\section{Medication: over or underused?}

Central to the doubts many professionals and parents articulate in regard to ADHD, are concerns about the potential overuse of medication and the unknown impact of medication on the developing brain. There is a deeply held conviction, by many, that other therapeutic modalities are de facto more appropriate for children. Unfortunately, despite a broad swathe of research over many years focusing on an array of therapeutic approaches, to date the only evidencedbased inputs for ADHD are parenting and medication (Sonuga-Barke et al. 2013). However, no evidence exists to allay fears as to the impact of medication on the developing brain. The recent controversial Cochrane review (Storebø et al. 2015) which cast doubt on the true effectiveness of medication and which has been subsequently extensively rebutted, particularly due to the unorthodox interpretation of 'bias' utilised by the Cochrane group, did little to promote an accurate understanding of the key role that medication plays for many children in remediating symptoms and enhancing quality of life (Banaschewski et al. 2015).

\section{ADHD in adulthood}

Without treatment, children with ADHD are more likely to go on to drop out of school, be involved in road traffic accidents, have unwanted pregnancies, misuse alcohol and drugs, enter the criminal justice system, experience relationship difficulties and struggle to sustain employment (Barkley et al. 2006). Unsurprisingly, additional mental health difficulties in adulthood are much more common in those with ADHD including mood disorders, anxiety disorders, personality disorders and 
substance misuse (Almeida Montes et al. 2007). Estimates vary of rates of untreated ADHD in adults attending mental health service with a prevalence of up to $20 \%$ reported within this edition although a limitation of the study was the use of an ADHD screening tool rather than a more comprehensive diagnostic assessment. Understandably, adult colleagues already underresourced and oversubscribed with 'traditional' severe and enduring mental illnesses are questioning their role in taking on the treatment of this large population of service users whose needs are currently not being met within existing service frameworks. This presents a major gap in service provision for this population which requires urgent attention from the perspective of healthcare managers and political leaders.

\section{Service implications}

There has been much recent focus on the fact that mental health services are 'weakest at the point of greatest need'; that is to say at the transition boundary (Singh et al. 2005). Within that group of adolescents with recognised mental health difficulties at this stage, those with ADHD are the single most likely diagnostic group to be lost in the transition gap as evidenced by both the TRACK and ITRACK studies. Indeed, in a recent secondary analysis of ITRACK data which involved a case note review, none of the teenagers with ADHD were successfully transitioned to adult public sector Mental Health $(\mathrm{MH})$ services (McNicholas et al. 2015).

\section{Ethical considerations and practical challenges}

The existing transition data raises significant ethical questions and practical challenges for child psychiatrists; where does responsibility begin and end for adolescents past the age of the transition boundary for whom no services are available? Similarly, what are the merits of raising awareness of ADHD as an adult condition, if no public sector services exist? Even when adult ADHD services have been developed, it is not always followed by CAMHS referral of ADHD cases. Whilst development in adult ADHD MH services are welcome, and part of the National Clinical programme for ADHD's remit, that alone is not sufficient. As public awareness increases, so too will the implications of this acknowledged service deficit (Ogundele, 2013). It is hoped that this special edition will play a helpful role in highlighting the reality of ADHD across the lifespan and the right of those affected to appropriate and accessible services at all stages of their lives.

\section{Financial support}

This article received no specific grant from any funding agency, commercial or not-for-profit sectors.

\section{Conflicts of Interest}

B.G. and F.M. have no conflicts of interest to disclose.

\section{Ethical Standards}

The author asserts that all procedures contributing to this work comply with the ethical standards of the relevant national and institutional committee on human experimentation with the Helsinki Declaration of 1975 , as revised in 2008 .

\section{References}

Almeida Montes LG, Hernandez Garcia AO, RicardoGarcell J (2007). ADHD prevalence in adult outpatients with nonpsychotic psychiatric illnesses. Journal of Attention Disorders 11, 150-156.

American Psychiatric Association (1952). Diagnostic and Statistical Manual of Mental Disorders. American Psychiatric Association: Washington, DC.

American Psychiatric Association (1968). Diagnostic and Statistical Manual of Mental Disorders, 2nd edn. American Psychiatric Association: Washington, DC.

American Psychiatric Association (1980). Diagnostic and Statistical Manual of Mental Disorders, 3rd edn. American Psychiatric Association: Washington, DC.

American Psychiatric Association (1987). Diagnostic and Statistical Manual of Mental Disorders, 3rd edn, revised. American Psychiatric Association: Washington, DC.

Banaschewski T, Buitelaar J, Chui CS, Coghill D, Cortese S, Simonoff E, Wong IC (2016). Methylphenidate for ADHD in children and adolescents: throwing the baby out with the bathwater. Evidence-Based Mental Health 19, 97.

Barkley RA, Fischer M, Smallish L, Fletcher K (2006). Young adult outcomes of hyperactive children: adaptive functioning in major life activities. Journal of the American Academy of Child and Adolescent Psychiatry 45, 192-202.

Biederman J, Faraone SV, Monuteaux MC, Bober M, Cadogen E (2004). Gender effects on attention-deficit/ hyperactivity disorder in adults, revisited. Biological Psychiatry 55, 692-700.

Caci H, Doepfner M, Asherson P, Donfrancesco R, Faraone SV, Hervas A, Fitzgerald M (2014). Daily life impairments associated with self-reported childhood/ adolescent attention-deficit/hyperactivity disorder and experiences of diagnosis and treatment: results from the European Lifetime Impairment Survey. European Psychiatry 29, 316-323.

Cortese S, Kelly C, Chabernaud C, Proal E, Di Martino A, Milham MP, Castellanos FX (2012). Toward systems neuroscience of ADHD: a meta-analysis of $55 \mathrm{fMRI}$ studies. American Journal of Psychiatry 169, 1038-1055.

Davenport ND, Karatekin C, White T, Lim KO (2010). Differential fractional anisotropy abnormalities in adolescents with ADHD or schizophrenia. Psychiatry Research: Neuroimaging 181, 193-198.

Dickstein SG, Bannon K, Castellanos FX, Milham MP (2006). The neural correlates of attention deficit hyperactivity 
disorder: an ALE meta-analysis. Journal of Child Psychology and Psychiatry 47, 1051-1062.

Ellison-Wright I, Ellison-Wright Z, Bullmore E (2008). Structural brain change in Attention Deficit Hyperactivity Disorder identified by meta-analysis. BMC Psychiatry 8,51 .

Hayden J, Flood M, McNicholas F (2015). ADHD in children: a path to free medicines. Irish Journal of Medical Science.

Health Service Executive (2014). Fifth Annual Child \& Adolescent Mental Health Service Report 2012-2013. HSE: Naas.

McGorry PD, Killackey EJ (2002). Early intervention in psychosis: a new evidence based paradigm. Epidemiologia e Psichiatria Sociale 11, 237-247.

McNicholas F, Adamson M, McNamara N, Gavin B, Paul M, Ford T, Barry S, Dooley B, Coyne I, Cullen W, Singh SP (2015). Who is in the transition gap? Transition from CAMHS to AMHS in the Republic of Ireland. Irish Journal of Psychological Medicine 32, 61-69.

Novik TS, Hervas A, Ralston SJ, Dalsgaard S, Pereira RR, Lorenzo MJ, ADORE Study Group (2006). Influence of gender on attention-deficit/hyperactivity disorder in Europe-ADORE. European Child \& Adolescent Psychiatry 15, i15-i24.

Ogundele MO (2013). Transitional care to adult ADHD services in a North West England district. Clinical Governance: An International Journal 18, 210-219.

Polanczyk G1, de Lima MS, Horta BL, Biederman J, Rohde LA (2007). The worldwide prevalence of ADHD: a systematic review and metaregression analysis. American Journal of Psychiatry 164, 942-948.

Proal E, Reiss PT, Klein RG, Mannuzza S, Gotimer K, Ramos-Olazagasti MA, Milham MP (2011). Brain gray matter deficits at 33-year follow-up in adults with attentiondeficit/hyperactivity disorder established in childhood. Archives of General Psychiatry 68, 1122-1134.

Sayal K, Prasad V, Daley D, Ford T, Coghill D (2017). ADHD in children and young people: prevalence, care pathways \& service provision. Lancet Psychiatry 5(2), 175-186.

Sayal K, Taylor E, Beecham J, Byrne P (2002). Pathways to care in children at risk of attention-deficit deficit hyperactivity disorder. British Journal of Psychiatry 181, 43-48.
Singh I (2008). Beyond polemics: science and ethics of ADHD. Nature Reviews Neuroscience 9, 957e964.

Singh I (2011). A disorder of anger and aggression: children's perspectives on attention deficit/hyperactivity disorder in the UK. Social Science \& Medicine 73(6), 889-896.

Singh SP, Evans N, Sireling L, Stuart H (2005). Mind the gap: the interface between child and adult mental health services. Psychiatric Bulletin 29, 292-294.

Skounti M, Philalithis A, Galanakis E (2007). Variations in prevalence of attention deficit hyperactivity disorder worldwide. European Journal of Pediatrics 166, 117-123.

Sonuga-Barke EJ, Brandeis D, Cortese S, Daley D, Ferrin M, Holtmann M, Stevenson J, Danckaerts M, van der Oord S, Döpfner M, Dittmann RW, Simonoff E, Zuddas A, Banaschewski T, Buitelaar J, Coghill D, Hollis C, Konofal E, Lecendreux M, Wong IC, Sergeant J, European ADHD Guidelines Group (2013). Nonpharmacological interventions for ADHD: systematic review and metaanalyses of randomized controlled trials of dietary and psychological treatments. American Journal of Psychiatry 170, 275-289.

Storebø OJ, Ramstad E, Krogh HB, Nilausen TD, Skoog M, Holmskov M, Rosendal S, Groth C, Magnusson FL, Moreira-Maia CR, Gillies D, Buch Rasmussen K, Gauci D, Zwi M, Kirubakaran R, Forsbøl B, Simonsen E, Gluud C (2015). Methylphenidate for children and adolescents with attention deficit hyperactivity disorder (ADHD). Cochrane Database of Systematic Reviews, (11), Art. No.: CD009885. DOI: 10.1002/14651858.CD009885.pub2.

Tatlow-Golden M, Prihodova L, Gavin B, Cullen W, McNicholas F (2017). What do general practitioners know about ADHD? Attitudes and knowledge among firstcontact gatekeepers: systematic narrative review. BMC Family Practice 17, 129.

Timimi S, Taylor E (2004). ADHD is best understood as a cultural construct. British Journal of Psychiatry 184, 1.

Willcutt EG (2012). The prevalence of DSM-IV attentiondeficit/hyperactivity disorder: a meta-analytic review. Neurotherapeutics 9, 490-499.

Wright N, Moldavsky M, Schneider J, Chakrabarti I, Coates J, Daley D, Sayal K (2015). Practitioner review: pathways to care for ADHD-a systematic review of barriers and facilitators. Journal of Child Psychology and Psychiatry 56, 598-617. 